\title{
INMIGRACIÓN Y EMPLEO EN COSTA RICA: UN ANÁLISIS CON PERSPECTIVA DE GÉNERO A PARTIR DE LA ENCUESTA CONTINUA DE EMPLEO
}

\author{
IMMIGRATION AND EMPLOYMENT IN COSTA RICA: AN ANALYSIS WITH A GENDER \\ PERSPECTIVE BASED ON THE CONTINUING EMPLOYMENT SURVEY
}

\section{IMIGRAÇÃO E EMPREGO NA COSTA RICA: UMA ANÁLISE COM A PERSPECTIVA DE GÊNERO A PARTIR DA PESQUISA CONTÍNUA DE EMPREGO}

\section{Roxana Morales Ramos ${ }^{1}$}

\begin{abstract}
Resumen
El objetivo de la investigación es caracterizar a la población inmigrante (desde una perspectiva de género), así como su participación en el mercado laboral costarricense, de manera que los resultados puedan ser utilizados por otras personas investigadoras interesadas en temas migratorios, así como por autoridades de gobierno y organizaciones sociales, para la elaboración de políticas públicas en esta materia. En ese sentido, en el documento se presenta un análisis, a partir de información extraída y procesada de la base de datos de la Encuesta Continua de Empleo (ECE), que trimestralmente realiza el Instituto Nacional de Estadística y Censos de Costa Rica (INEC); particularmente de los datos para el segundo trimestre de 2018.
\end{abstract}

Se presenta una caracterización de las personas inmigrantes (nacidas en otro país) en el nivel nacional, por región de planificación, por país de procedencia, por grupos de edad y por sexo. Adicionalmente, se realiza un análisis detallado de las personas ocupadas, desempleadas, y del perfil educativo de la población inmigrante en fuerza de trabajo.

Palabras clave: empleo; desempleo; género; migración; Costa Rica; INEC

DOi: https://doi.org/10.15359/eys.23-54.5

Fecha de recepción: 02-08-2018. Fechas de reenvíos: 05-10-2018, 22-10-2018. Aceptado el 26-10-2018. Publicado el 29-10-2018.

${ }^{1}$ Máster en Economía del Desarrollo con énfasis en Gestión Macroeconómica y Políticas Públicas. Académica, investigadora y coordinadora del Observatorio Económico y Social de la Escuela de Economía de la Universidad Nacional (OES-UNA), Costa Rica. Correo electrónico: rmorale@una.ac.cr 50

Roxana Morales Ramos

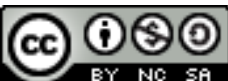

Revista Economía y Sociedad by Universidad Nacional is licensed under a CreativeCommons Reconocimiento-NoComercial- 


\begin{abstract}
The objective of this paper is to characterize the immigrant population (from a gender perspective), as well as their participation in the Costa Rican labor market, for results to be used by other researchers interested in migration issues, government authorities, and social organizations to prepare related public policies. In this sense, the document presents an analysis, based on the information collected and processed from the data for the second quarter of 2018 of the Continuing Employment Survey (ECE), which is conducted quarterly by the National Institute of Statistics and Census of Costa Rica (INEC).

Immigrants (individuals born in another country) are characterized at a national level by planning region, country of origin, age group, and sex. In addition, a detailed analysis is included of employed and unemployed individuals and the educational profile of the immigrant population in the work force.
\end{abstract}

Keywords: employment; unemployment; gender; migration; Costa Rica; INEC

\title{
Resumo
}

O objetivo da pesquisa é caracterizar a população imigrante (a partir de uma perspectiva de gênero), bem como a sua participação no mercado de trabalho da Costa Rica, de modo que os resultados possam ser usados por outros pesquisadores interessados em temas migratórios, bem como pelas autoridades do governo e organizações sociais, para a elaboração de políticas públicas nesta matéria. Nesse sentido, apresenta-se no documento uma análise feita a partir das informações extraídas e processadas da base de dados da Pesquisa Contínua de Emprego (ECE, por suas siglas em espanhol), trimestralmente realizada pelo Instituto Nacional de Estatísticas e Censos da Costa Rica (INEC); particularmente dos dados do segundo trimestre de 2018.

Apresenta-se uma caracterização das pessoas imigrantes (nascidas em outro país) em âmbito nacional, por região de planejamento, por país de origem, por faixa etária e por sexo. Além disso, realiza-se uma análise detalhada das pessoas empregadas, desempregadas e do perfil educacional da população imigrante na força de trabalho.

Palavras-chave: emprego; desemprego; gênero; migração Costa Rica; INEC 


\section{Introducción}

En las últimas décadas actuales, y especialmente en los últimos años, la inmigración se ha convertido en un tema relevante para Costa Rica. Para Morales (2008), este es considerado "un país pequeño, pero con una pluralidad migratoria, como receptor de inmigrantes, temporales y permanentes, y al mismo tiempo como expulsor y de tránsito" (p. 10); es decir, es una nación que recibe una importante cantidad de migrantes pero que, a su vez, expulsa personas.

El país vive una situación apremiante debido a la crisis política que sufre en Nicaragua, la cual ha provocado un incremento en la entrada de población nicaragüense que solicita refugio ${ }^{2}$, así como un aumento en las solicitudes de visas a Costa Rica en Nicaragua ${ }^{3}$. Esto a su vez ha provocado que algunos grupos de la población se manifiesten en contra de esta población migrante, incluso mediante actos xenofóbicos y de discriminación. Por ello, es necesario conocer de primera mano, con información fiable y reciente, la situación de la inmigración en el país.

El objetivo del presente artículo es caracterizar a la población inmigrante -desde una perspectiva de género ${ }^{4}$-, así como su participación en el mercado laboral costarricense, con la información más reciente disponible, de manera que permita comprender el contexto actual del país en esta materia y, a su vez, sirva de insumo para la toma de decisiones, como por ejemplo sobre: políticas para el otorgamiento de permisos de trabajo (determinar cantidad y actividades), políticas para regularizar la población migrante, reducción de la informalidad, reducción de las brechas de género, entre otras.

Para el desarrollo de la investigación se utiliza como base la Encuesta Continua de Empleo (ECE), realizada trimestralmente por el Instituto Nacional de Estadística y Censos (INEC):

\footnotetext{
${ }^{2}$ La Dirección General de Migración y Extranjería manifestó el 25 de junio de 2018 que "Por semana y solo los lunes se otorgan 1.000 citas, aunque la atención se divide entre los cinco días de la semana, es decir, que se recibe a 200 personas diariamente" (Jiménez y Recio, 2018, párr. 7).

${ }^{3}$ En una nota de prensa del periódico La Nación, con fecha 16 de julio de 2018, el embajador de Costa Rica en Nicaragua, Eduardo Trejos, manifestó que las oficinas consulares de Costa Rica en Nicaragua registraron un aumento del $42 \%$ en las solicitudes de visas, para un promedio de 600 peticiones diarias en la sede de Managua, y otras 320 en la de Chinandega, con un total de 920 . Además, indicó que hace un año el total de solicitudes entre ambos puestos no llegaba a las 650 (Chinchilla, 2018).

${ }^{4}$ Para Susana Gamboa, presidenta de la asociación Agenda de las Mujeres de Argentina, "la perspectiva de género, en referencia a los marcos teóricos adoptados para una investigación, capacitación o desarrollo de políticas o programas, implica: a) reconocer las relaciones de poder que se dan entre los géneros, en general favorables a los varones como grupo social y discriminatorias para las mujeres; b) que dichas relaciones han sido constituidas social e históricamente y son constitutivas de las personas; c) que las mismas atraviesan todo el entramado social y se articulan con otras relaciones sociales, como las de clase, etnia, edad, preferencia sexual y religión". (Gamboa, 2018, párr. 5). En este sentido "la perspectiva de género opta por una concepción epistemológica que se aproxima a la realidad desde las miradas de los géneros y sus relaciones de poder" (Gamboa, 2018, párr. 9).
}

52

Roxana Morales Ramos

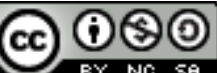

Revista Economía y Sociedad by Universidad Nacional is licensed under a CreativeCommons Reconocimiento-NoComercial- 
La ECE es una investigación estadística que recolecta información periódica en los hogares del país para conocer la evolución de los principales indicadores del mercado laboral en el corto plazo y captar de esa forma, las variaciones estacionales de la participación de la población en ese mercado laboral como: ocupada, desocupada e inactiva (INEC, 2012, p. 7).

Dicha encuesta es realizada desde el tercer trimestre de 2010, y la última disponible al momento de escribir este artículo, corresponde al segundo trimestre de 2018. De esta es que se extrae y procesa la información que se presentará a lo largo del documento.

Para obtener la información de la población inmigrante en Costa Rica, se procedió a realizar cruces de variables utilizando como variable principal la "población nacida en otro país". En este sentido, se analizan datos para la población inmigrante total, por sexo, por grupos de edad, por región de planificación ${ }^{5}$ y por país de procedencia. Es importante mencionar que solamente se hace distinción entre dos géneros: masculino y femenino, debido a que la ECE solamente hace la distinción entre hombres y mujeres y no incluye la diversidad sexual en sentido amplio (orientación sexual o identidad de género).

Con respecto a las regiones, es importante ubicarlas geográficamente a cada una de ellas, ya que esto permite comprender mejor los resultados de los análisis (ver Figura 1).

Adicionalmente, para comprender los resultados resulta necesario conocer las definiciones de los principales indicadores, entre ellos que la fuerza de trabajo o población económicamente activa es aquella que tiene 15 años y más y que en la semana de referencia de la encuesta se encuentra ocupada o desempleada. Por su parte, para considerar que una persona está desempleada, esta debe haber buscado activamente un empleo en las últimas cuatro semanas de referencia de la encuesta (si no buscó trabajo no se considera desempleada).

Para considerar que una persona se encuentra ocupada, esta debió participar en la producción de bienes y servicios económicos por los menos una hora en la semana de referencia de la encuesta. Lo anterior se resume en la Figura $\underline{2}$.

\footnotetext{
5 “La regionalización en el territorio nacional es designada por el Sistema Nacional de Planificación (SNP) del Ministerio de Planificación Nacional y Política Económica (MIDEPLAN) de Costa Rica. El país se encuentra dividido en seis regiones de planificación territorial: Central, Chorotega, Pacífico Central, Brunca, Huetar Caribe, y Huetar Norte" (INEC, 2016, p. 15).
} 


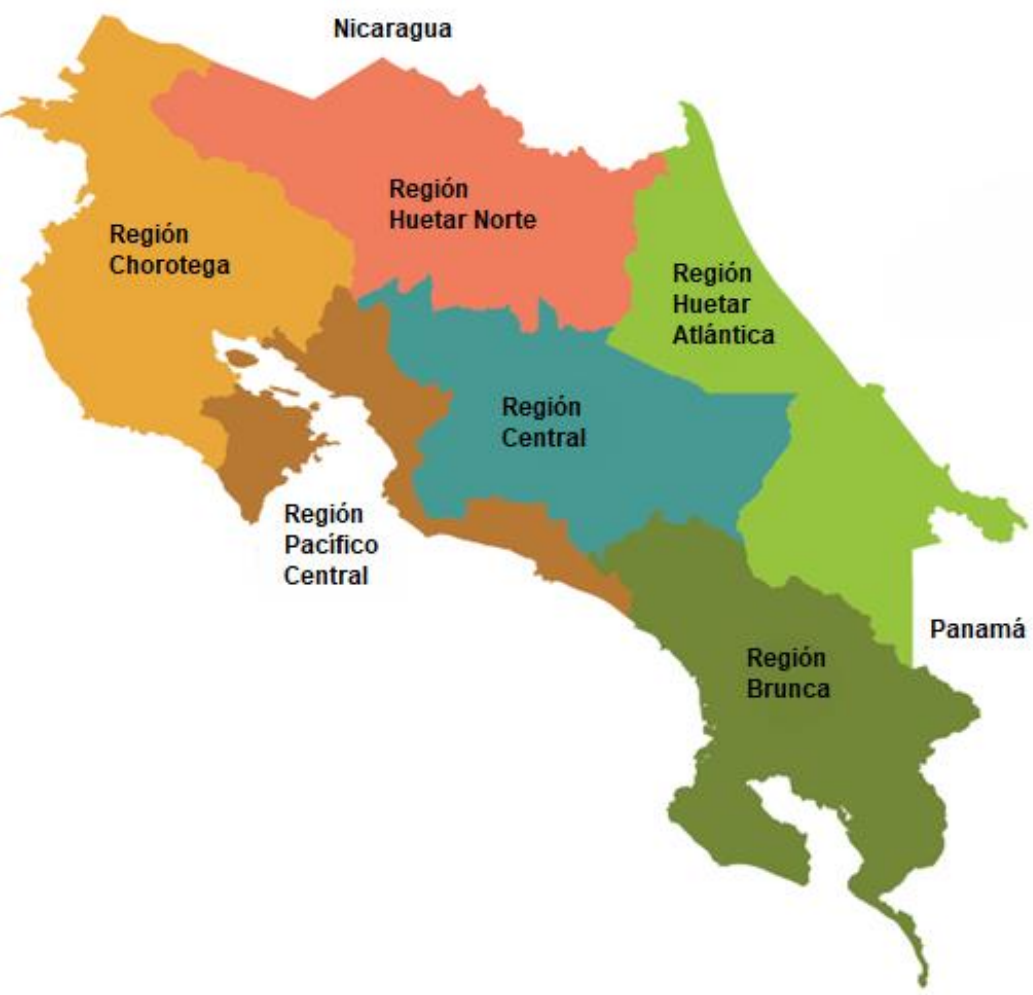

Figura 1. Costa Rica: Regiones de Planificación. Fuente: INEC, 2016, p. 17

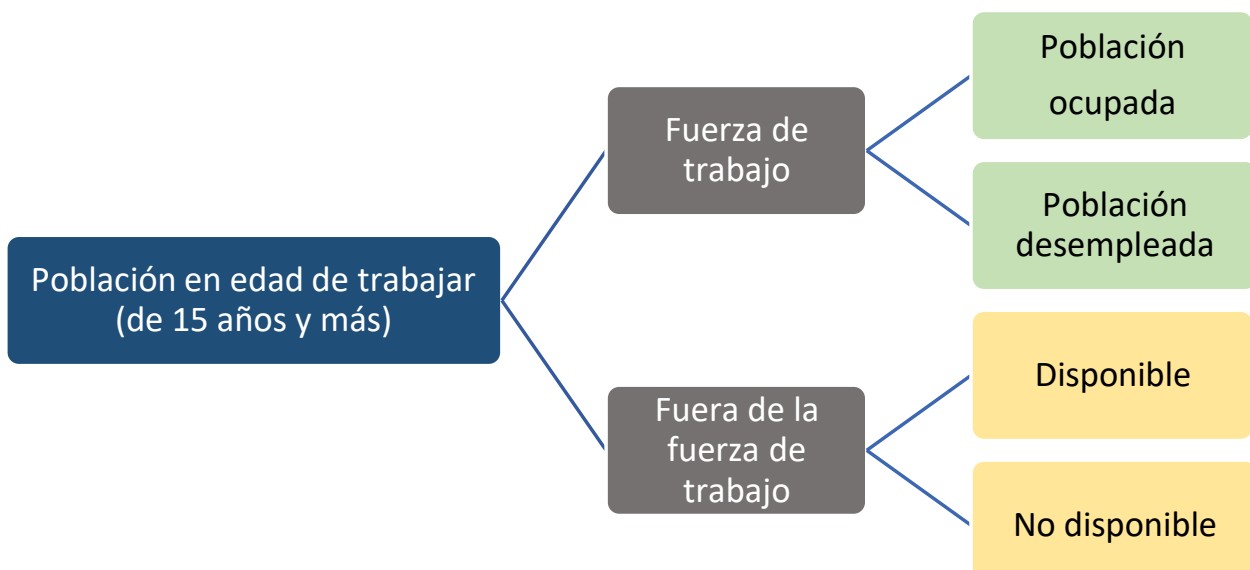

Figura 2. Costa Rica: Conceptos básicos de la Encuesta Continua de Empleo del INEC. Fuente: elaboración propia, con base en los datos del INEC.

54

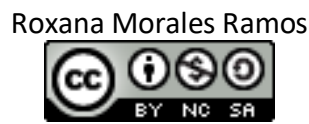

Revista Economía y Sociedad by Universidad Nacional is licensed under a CreativeCommons Reconocimiento-NoComercialCompartirlgual 4.0 Internacional License. Creado a partir de la obra en http://www.revistas.una.ac.cr/index.php/economia 
El presente documento se desarrolla en seis apartados. En el primero se presenta un breve resumen del perfil de las personas inmigrantes en Costa Rica y la evolución de las remesas (enviadas y recibidas). En el segundo, se realiza una caracterización general de la población inmigrante, a partir de los datos de la ECE, por sexo, grupos de edad, país de origen y región. En el tercero, se hace un análisis de la población inmigrante por condición de actividad, es decir, la ocupada, desempleada y fuera de la fuerza de trabajo; a partir de estos datos se presentan algunos indicadores, como por ejemplo la tasa de desempleo y la tasa de participación, totales y por sexo. En el cuarto, se efectúa una caracterización de la población inmigrante ocupada, lo que permite determinar en cuáles actividades económicas participan más los hombres y las mujeres nacidos en otro país, así como la posición en el empleo (asalariados, cuenta propia, empleados y auxiliar no remunerado), el porcentaje de ocupados con seguro por trabajo, ocupados informales, subempleados, entre otros.

En el apartado cinco, se presenta el perfil educativo de la población inmigrante en fuerza de trabajo (ocupada + desempleada), total y por país de origen (los más representativos) y, finalmente, en el apartado seis, se presentan las principales conclusiones.

\section{Perfil general de las personas inmigrantes en Costa Rica y evolución de las remesas}

El informe del Banco Central de Costa Rica titulado Aspectos socioeconómicos de las remesas familiares en Costa Rica, 2016 (BCCR, 2018), revela que, del total de personas inmigrantes mayores de 18 años que residen en Costa Rica, el $78 \%$ son de origen nicaragüense, el $7 \%$ de algún otro país centroamericano y el restante $15 \%$ de otras nacionalidades. Además, indica que, del total de la población mayor de 18 años en el país, el 11,3 \% corresponde a inmigrantes (peso de los inmigrantes en la población mayor de 18 años en Costa Rica).

Con respecto a las causas de migración hacia nuestro país, según este mismo informe del BCCR (2018), entre los nicaragüenses, el 38,25 \% indica que su migración se debe a la cercanía con Costa Rica, el 29,13\% porque vino con su familia, el 14,95\% por oportunidad de trabajo, el 5,44\% por estabilidad política y económica, y el restante $12,23 \%$ indica que: por turismo, porque le atrae el país, por matrimonio, por estudios, por negocios, y otros.

Con respecto a otras nacionalidades, el motivo de mayor peso para venir a Costa Rica es por "vínculos familiares" (33,91\%), seguido de "estabilidad política y económica" (11,3\%), "porque le atrae el país" (10,43 \%), "por una oportunidad de empleo" (8,7 \%), "por estudios" (6,96 \%), entre otros.

En resumen, "los vínculos familiares son uno de los principales motivos por los cuales los inmigrantes eligieron a Costa Rica para residir" (BCCR, 2018, p. 9), así como la cercanía entre los países: "tomando en cuenta que Costa Rica y Nicaragua son países limítrofes, es de esperar que 
un porcentaje considerable de los inmigrantes encuestados, resaltaran la cercanía con su país de origen como otro motivo principal de la migración" (BCCR, 2018, p. 9).

Con respecto a las remesas enviadas por trabajadores extranjeros a sus países de origen, en los últimos años se han mantenido en alrededor de 330 millones de dólares anuales y las remesas recibidas en cerca de 500 millones de dólares anuales (Figura $\underline{3}$ ), según datos extraídos de la Balanza de Pagos publicada por el Banco Central de Costa Rica. En general, el país es receptor neto de remesas. Es importante observar en la Figura $\underline{3}$ el crecimiento de las remesas (migración), tanto las que entran como las que salen, a partir del año 2000, con una leve baja en el periodo 2008-2010, producto de la crisis financiera internacional que afectó los flujos migratorios y el empleo (por tanto, los ingresos de los migrantes).

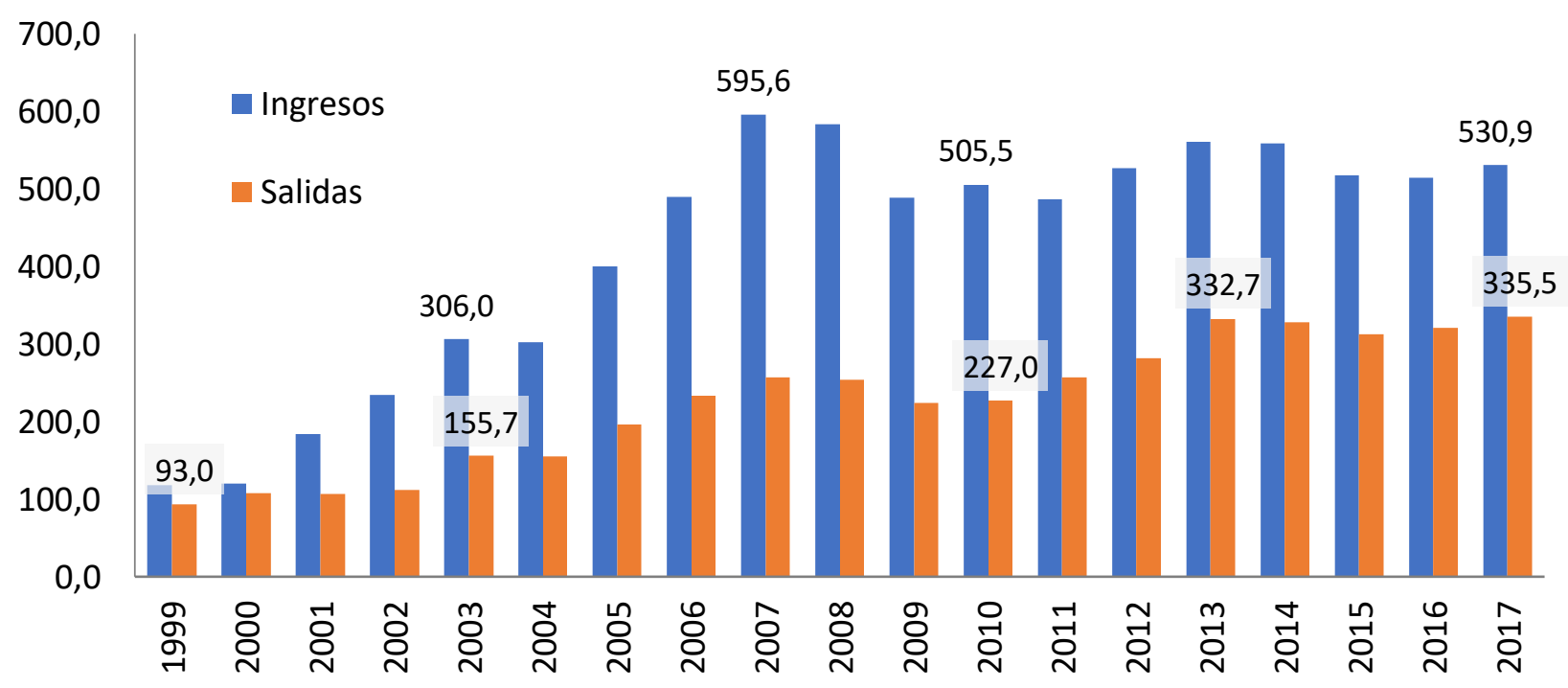

Figura 3. Remesas de trabajadores en millones de USD. Fuente: elaboración propia, con datos de la Balanza de Pagos, BCCR.

\section{Caracterización de la población inmigrante}

Según datos de la Encuesta Continua de Empleo, actualmente viven en Costa Rica cerca de 429 mil personas nacidas en otro país, lo que representa el 8,6 \% de la población. Dicho porcentaje ha oscilado entre el $7 \%$ y $9 \%$ en los últimos 7 años y medio, tal como se muestra en la Figura $\underline{4}$. 


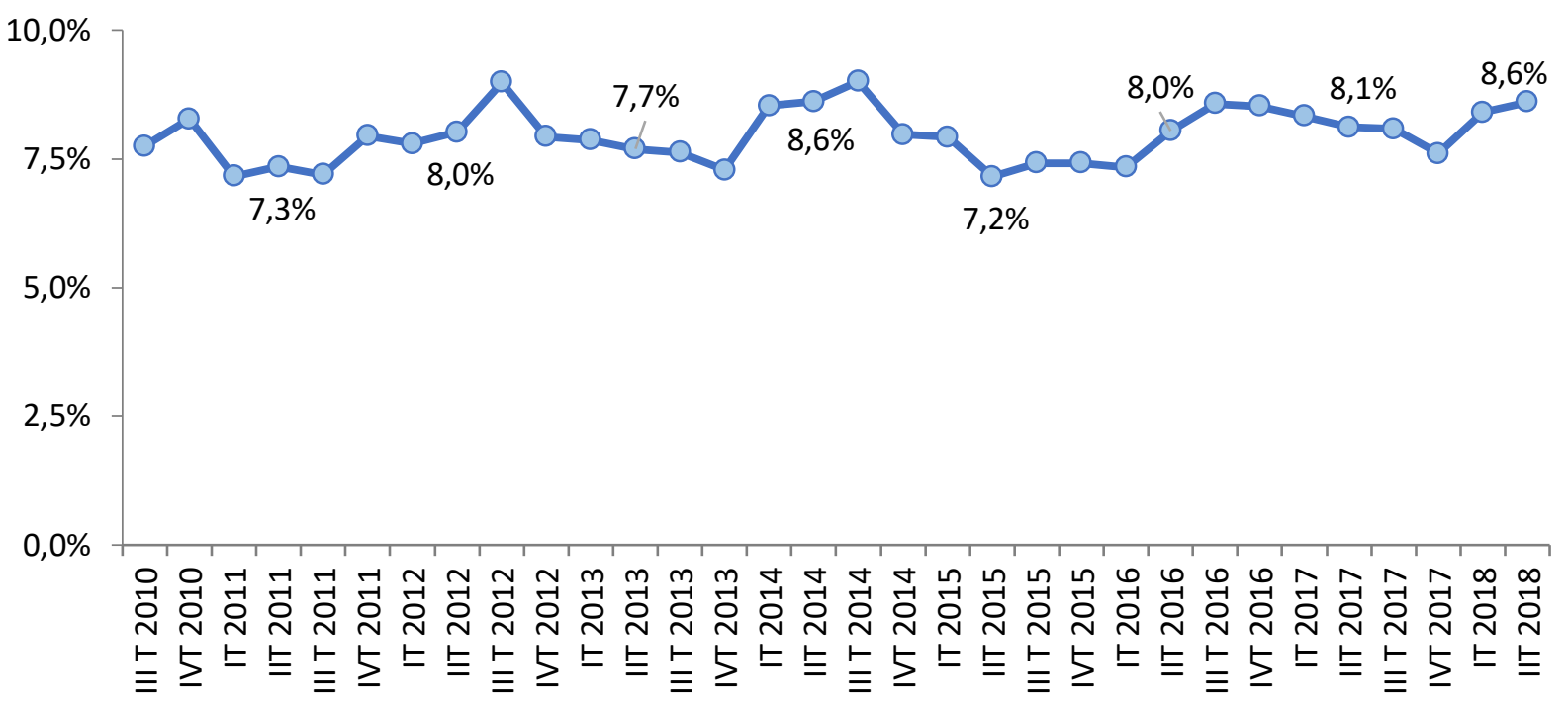

Figura 4. Costa Rica: Porcentaje de población nacida en otro país respecto al total de población. IIIT 2010 - IIT 2018. Fuente: elaboración propia, con datos de la ECE del INEC.

Al analizar la información de la ECE, para el segundo trimestre de 2018, por región de planificación y por sexo, se determina que:

- En el país viven 429.408 personas nacidas en otro país (inmigrantes). De ellas, el 65,6 \% residen en la Región Central (281 709 personas), el 15,4 \% en la Huetar Norte (66 208), el $7,9 \%$ en la Huetar Caribe (33,775), el 5,6 \% en la Chorotega (23 875), el 3,4 \% en la Pacífico Central (14 641) y el $2,1 \%$ en la Brunca ( 9 107). (Tabla 1)

Tabla 1

Costa Rica: composición de la población nacida en otro país por región y sexo. II trimestre 2018

\begin{tabular}{lccc}
\hline Región & Hombre & Mujer & Total \\
\hline Central & $64,6 \%$ & $66,6 \%$ & $65,6 \%$ \\
Chorotega & $5,4 \%$ & $5,8 \%$ & $5,6 \%$ \\
Pacífico Central & $3,7 \%$ & $3,1 \%$ & $3,4 \%$ \\
Brunca & $2,2 \%$ & $2,0 \%$ & $2,1 \%$ \\
Huetar Caribe & $8,4 \%$ & $7,4 \%$ & $7,9 \%$ \\
Huetar Norte & $15,8 \%$ & $15,1 \%$ & $15,4 \%$ \\
Total & $100,0 \%$ & $100,0 \%$ & $100,0 \%$ \\
\hline
\end{tabular}

Fuente: elaboración propia, con datos de la ECE del INEC.

- Del total de la población de cada región, en la región Huetar Norte es donde existe una mayor población inmigrante: 16,3 \% de su población es nacida en otro país y de ella, el 97 \% corresponde a nicaragüenses (Tabla 2). Esta situación podría responder a su cercanía 
con Nicaragua y a que las principales actividades realizadas en esta región son agropecuarias, por lo tanto, es esta una de las ramas de actividad donde más participa la población inmigrante.

Tabla 2

Costa Rica: población nacida en otro país por región y sexo. II trimestre 2018

\begin{tabular}{lccc}
\hline \multirow{2}{*}{ Región } & \multicolumn{3}{c}{ \% de la población nacida en otro país } \\
\cline { 2 - 4 } Total, país & Hombres & Mujeres & Total \\
\hline Central & $\mathbf{8 , 4} \%$ & $\mathbf{8 , 8 \%}$ & $\mathbf{8 , 6 \%}$ \\
Chorotega & $\mathbf{8} \%$ \% & $9,3 \%$ & $9,1 \%$ \\
Pacífico Central & $5,9 \%$ & $6,7 \%$ & $6,3 \%$ \\
Brunca & $5,2 \%$ & $4,8 \%$ & $5,0 \%$ \\
Huetar Caribe & $2,6 \%$ & $2,4 \%$ & $2,5 \%$ \\
Huetar Norte & $7,7 \%$ & $7,4 \%$ & $7,5 \%$ \\
\hline
\end{tabular}

Fuente: elaboración propia, con datos de la ECE del INEC.

- Al analizar la composición de la población inmigrante por sexo, se observa que, en el nivel nacional hay más mujeres (216 800) que hombres (212 608) (Tabla $\underline{3}$ ), sin embargo, en el ámbito regional, no hay gran diferencia, es decir, la participación se mantiene muy parecida entre hombres y mujeres (ver Tabla 2). Por ejemplo, en la Región Central, del total de mujeres que viven ahí, el 9,3 \% son mujeres inmigrantes y del total de hombres, el $8,9 \%$ corresponde a hombres inmigrantes.

- Con respecto al país de origen, la mayoría de personas inmigrantes provienen de Nicaragua, Estados Unidos, Colombia y de otros países centroamericanos (ver Tabla $\underline{3}$ ).

- Adicionalmente, en la Tabla 3 se aprecia como la inmigración varía considerablemente según el país de procedencia y según sexo (hombres y mujeres). Llama la atención que, de El Salvador y Venezuela, la mayoría de los inmigrantes son mujeres. En el caso de los nicaragüenses, hay más mujeres que hombres, pero la diferencia es muy poca. Por su parte, en el caso de los estadounidenses, panameños y hondureños, la mayoría son hombres los que viven en Costa Rica. 
Tabla 3

Costa Rica: población nacida en otro país por sexo. II trimestre 2018

\begin{tabular}{lrrrr}
\hline \multicolumn{1}{c}{ País de nacimiento } & Total (personas) & Peso relativo (\%) & \% Hombres & \% Mujeres \\
\hline Nicaragua & 333568 & $77,7 \%$ & $47,5 \%$ & $52,5 \%$ \\
Otro país & 23552 & $5,5 \%$ & $48,7 \%$ & $51,3 \%$ \\
Estados Unidos & 17829 & $4,2 \%$ & $78,0 \%$ & $22,0 \%$ \\
Colombia & 14990 & $3,5 \%$ & $57,6 \%$ & $42,4 \%$ \\
Honduras & 8886 & $2,1 \%$ & $63,8 \%$ & $36,2 \%$ \\
Panamá & 8334 & $1,9 \%$ & $73,1 \%$ & $26,9 \%$ \\
El Salvador & 7997 & $1,9 \%$ & $27,6 \%$ & $72,4 \%$ \\
Venezuela & 7626 & $1,8 \%$ & $30,4 \%$ & $69,6 \%$ \\
México & 6437 & $1,5 \%$ & $57,4 \%$ & $42,6 \%$ \\
No especificado & 189 & $0,0 \%$ & $67,2 \%$ & $32,8 \%$ \\
\hline Total, inmigrantes & 429408 & $100,0 \%$ & $49,5 \%$ & $50,5 \%$ \\
\hline
\end{tabular}

Fuente: elaboración propia, con datos de la ECE del INEC.

- Al analizar la población nacida en otro país por grupos de edad, se observa que, cerca del $60 \%$ es mayor de 35 años y el restante $40 \%$ de 34 años o menos (Tabla 4).

Tabla 4

Costa Rica: población nacida en otro país por grupos de edad y sexo. II trimestre 2018

\begin{tabular}{lrrrr}
\hline \multicolumn{1}{c}{ Grupo de edad } & Hombre & Mujer & \multicolumn{1}{c}{ TOTAL } & \multicolumn{1}{c}{ Composición } \\
\hline 0 a 14 años & 16759 & 14161 & 30920 & $7,2 \%$ \\
15 a 24 años & 35571 & 29747 & 65318 & $15,2 \%$ \\
25 a 34 años & 36093 & 43805 & 79898 & $18,6 \%$ \\
35 a 44 años & 45483 & 56659 & 102142 & $23,8 \%$ \\
45 a 59 años & 50591 & 48568 & 99159 & $23,1 \%$ \\
60 y más & 27927 & 23729 & 51656 & $12,0 \%$ \\
Total & 212424 & 216728 & 429152 & $100,0 \%$ \\
\hline
\end{tabular}

Fuente: elaboración propia, con datos de la ECE del INEC.

Al desagregar la información de la población nacida en otro país, por grupos de edad y por país de origen, llama la atención la siguiente información:

- Nicaragüenses: el 7,3 \% tiene 60 años y más, el 22,8 \% tiene entre 45 y 59 años y, el 70 \% menos de 44 años. Predomina la población joven.

— Salvadoreños: el 63,7 \% tiene 60 años y más, el 18,6 \% tiene entre 45 y 59 años y, el 17,7 $\%$ menos de 44 años. Predomina la población adulta mayor y dentro de ellos la mayoría mujeres (el 72,4\%). 
- Hondureños: el 34,9 \% tiene 60 años y más, el 44 \% tiene entre 45 y 59 años y, el $21 \%$ menos de 44 años. En su mayoría es población mayor de 45 años y hombres (el 63,8 \%).

- Panameños: el 20,3 \% tiene 60 años y más, el 30,9 \% tiene entre 45 y 59 años y, el 48,8 \% menos de 44 años. Es población relativamente joven y en su mayoría son hombres (el 73,1\%).

- Colombianos: el 16,4 \% tiene 60 años y más, el 27,6 \% tiene entre 45 y 59 años y, el $56 \%$ menos de 44 años. Predomina la población relativamente joven y hay más hombres que mujeres.

- Estadounidenses: el 26,9 \% tiene 60 años y más, el $4 \%$ tiene entre 45 y 59 años y, el 69,2 \% menos de 44 años. Predomina la población joven y de sexo masculino (el 78 \%).

- Mexicanos: el $15 \%$ tiene 60 años y más y el 85 \% menos de 44 años. Es población bastante joven y hay más hombres que mujeres.

- Venezolanos: el $13 \%$ tiene 60 años y más, el 29,6 \% tiene entre 45 y 59 años y, el 57,3\% menos de 44 años. La mayoría son mujeres (el 69,6\%).

- Otros países: 34,7 \% tiene 60 años y más, el 34,1 \% tiene entre 45 y 59 años y, el 31,2 \% menos de 44 años. Estos datos podrían confirmar la preferencia que tienen las personas adultas mayores de otros países de pasar su vejez en Costa Rica, ya que el grupo de 60 años y más es el de mayor peso relativo.

\section{Condición de actividad de la población nacida en otro país}

Al analizar la información de la Encuesta Continua de Empleo para el segundo trimestre de 2018 con respecto a la población nacida en otro país, se obtiene que (Tabla $\underline{5}$ ):

- El 29,5 \% de la población nacida en otro país de 15 años y más, se encuentra fuera de la fuerza de trabajo. Entre las mujeres el porcentaje es del 44,7\% y entre los hombres del $13,8 \%$. En el nivel nacional los porcentajes son: $39,1 \%, 53,2 \%$ y $25,1 \%$, respectivamente. Como se desprende de los datos, también en la población inmigrante se repite la situación de que las mujeres participan en menor proporción que los hombres en el mercado laboral.

- La tasa de participación laboral de los inmigrantes en el país es del 70,5 \%, entre los hombres es del $86,2 \%$ y entre las mujeres del 55,3 \%. En el nivel nacional estos porcentajes son: $60,9 \%, 74,9 \%$ y $44,7 \%$, respectivamente. De lo anterior se desprende

60

Roxana Morales Ramos

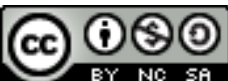

Revista Economía y Sociedad by Universidad Nacional is licensed under a CreativeCommons Reconocimiento-NoComercial- 
que, la tasa de participación de las mujeres inmigrantes es mayor que la del promedio nacional; quizá esto pueda explicarse por el objetivo principal de las personas migrantes, el cual consiste en alcanzar una mejor calidad de vida para sí mismos y para sus familias, realizable a través del empleo.

- La tasa de desempleo abierto entre los inmigrantes es del 5,7\%, es decir, del total de población nacida en otro país que buscó activamente trabajo en las últimas cuatro semanas de referencia de la encuesta, ese porcentaje indicó que no consiguió empleo. Esa tasa está por debajo de la tasa de desempleo nacional que fue del 8,7 \% en el segundo trimestre de 2018.

- Si se desagrega la tasa de desempleo por sexo, la de las mujeres inmigrantes es cuatro veces mayor que la de los hombres inmigrantes (10,4\% vs. 2,5\%); sin embargo, ambas tasas son menores que las del promedio nacional ( $12 \%$ y 6,6 \%, respectivamente) (ver Tabla $\underline{5}$ ). Con respecto a este indicador, vale la pena mencionar que las brechas de género en el ámbito nacional se reproducen también entre la población inmigrante, siendo que las mujeres tienen mayor dificultad para encontrar empleo.

- Del total de personas ocupadas en el país, el 12,3 \% corresponde a las nacidas en otro país. Entre las mujeres ocupadas ese porcentaje es del $12,6 \%$ y entre los hombres del $12,1 \%$.

- Del total de personas desempleadas en el país (población de 15 años y más que buscó trabajo activamente en las últimas cuatro semanas de referencia de la ECE, que equivale a 205.141 personas), el 7,8\% son inmigrantes. Del total de mujeres desempleadas en el país, el 10,7 \% corresponde a mujeres inmigrantes, y del total de hombres desempleados en el país, el 4,4 \% son hombres inmigrantes. (Ver Tabla $\underline{5}$ )

- De las 15093 personas inmigrantes desempleadas, el 80 \% son nicaragüenses, el 6,9\% colombianos, el 5,2 \% hondureños, el $5 \%$ venezolanos, el 1,4 \% panameños, y el resto de otros países.

Los anteriores datos, como se mencionó, dan cuenta de que entre los migrantes se replican las brechas de género que se presentan en el nivel nacional y que la mayoría de las personas inmigrantes ocupadas y desempleados son nacidas en Nicaragua. 
Tabla 5

Costa Rica: población nacida en otro país por grupos de edad según sexo. II trimestre 2018

\begin{tabular}{lrrr}
\hline Población nacida en otro país & Hombre & Mujer & Total \\
\hline Ocupado & 164491 & 100358 & 264849 \\
Desempleado & 4240 & 11663 & 15903 \\
Fuera de la fuerza de trabajo & 27061 & 90546 & 117607 \\
Fuerza de trabajo & 168731 & 112021 & 280752 \\
Tasa de desempleo abierto & $2,5 \%$ & $10,4 \%$ & $5,7 \%$ \\
\hline Población total Costa Rica & Hombre & Mujer & Total \\
\hline Ocupado & 1363162 & 796874 & 2160036 \\
Desempleado & 96557 & 108584 & 205141 \\
Fuera de la fuerza de trabajo & 489329 & 1028328 & 1517657 \\
Fuerza de trabajo & 1459719 & 905458 & 2365177 \\
Tasa de desempleo abierto & $6,6 \%$ & $12,0 \%$ & $8,7 \%$ \\
\hline
\end{tabular}

Fuente: elaboración propia, con datos de la ECE del INEC.

\section{Caracterización de la población inmigrante ocupada}

\section{Ocupados inmigrantes por sector de actividad}

De los tres sectores de actividad de la economía (primario, secundario y terciario o de servicios), los inmigrantes participan mayoritariamente en el sector servicios.

Del total de personas ocupadas nacidas en otro país, el 64,2 \% labora en el sector servicios, el $21,2 \%$ en el sector secundario y el $14,6 \%$ en el sector primario (Primer gráfico de la Figura 5).

Si se analiza por sexo, el panorama varía considerablemente, siendo que el $91 \%$ de las mujeres inmigrantes ocupadas laboran en el sector servicios, el $5 \%$ en el sector primario y el 4,1 \% en el secundario. Entre los hombres hay una mayor distribución entre los tres sectores: servicios $(47,8$ $\%)$, secundario $(31,7 \%)$ y primario $(20,4 \%)$. (Figura $\underline{5}$ )

62 


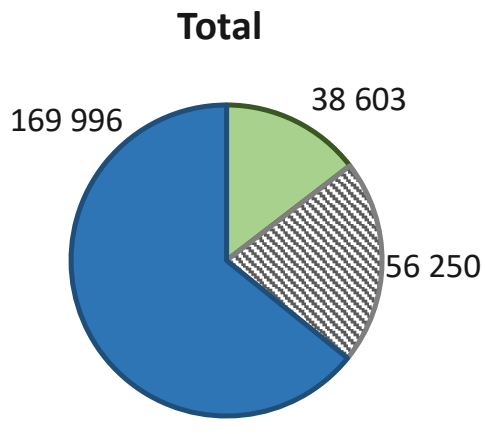

$\square$ Sector primario \$ Sector secundario

口 Sector servicios
Hombres

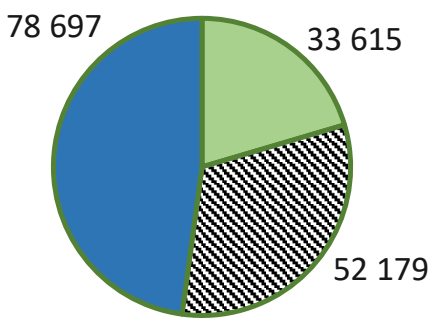

$\square$ Sector primario \$ Sector secundario

Sector servicios
Mujeres

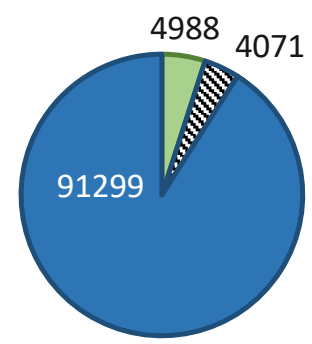

$\square$ Sector primario

\$ Sector secundario

Sector servicios

Figura 5. Costa Rica: población ocupada nacida en otro país por sector de actividad del empleo principal según sexo. II Trimestre, 2018. Fuente: elaboración propia, con datos de la ECE del INEC.

\section{Ocupados inmigrantes por grupo ocupacional}

En la Tabla $\underline{6}$ se observa la distribución de las actividades en las que se desempeña la población ocupada en Costa Rica nacida en otro país ${ }^{6}$. De los datos se desprende que las ocupaciones elementales son las que predominan, tanto entre los hombres como entre las mujeres inmigrantes (casi la mitad de los ocupados se ubican en este grupo) y, el segundo grupo de mayor importancia es el de trabajadores de los servicios y vendedores de comercios y mercados.

Por su parte, el grupo ocupacional donde hay una menor participación es el de directores $y$ gerentes, con apenas el 0,8 \% de las personas inmigrantes ocupadas. La anterior distribución puede estar relacionada con las políticas o condiciones de otorgamiento de permisos de trabajo establecidas por el Ministerio de Trabajo y Seguridad Social (MTSS) y por la Dirección General de Migración y Extranjería, donde el acceso a muchas actividades es limitado. En este sentido, a pesar de que algunos inmigrantes cuenten con un nivel educativo alto, no se les posibilita desenvolverse en las actividades para los cuáles se han especializado, y terminan en ocupaciones elementales en las cuales es donde hay más oportunidades de empleo para esta población, tanto en el ámbito formal como informal.

\footnotetext{
${ }^{6}$ Se utiliza la Clasificación de Ocupaciones de Costa Rica, COC 1988, (INEC, 2012).
} 
Tabla 6

Costa Rica: población ocupada nacida en otro país por grupo ocupacional del empleo principal según sexo. Il trimestre 2018

\begin{tabular}{|c|c|c|c|c|c|c|}
\hline $\begin{array}{l}\text { Grupo ocupacional del empleo principal } \\
\text { según COCR } 2011\end{array}$ & Hombre & Mujer & Total & Hombre & Mujer & Total \\
\hline Ocupaciones elementales & 75968 & 48138 & 124106 & $46,2 \%$ & $48,0 \%$ & $46,9 \%$ \\
\hline $\begin{array}{l}\text { Trabajadores de los servicios y } \\
\text { vendedores de comercios y mercados }\end{array}$ & 29696 & 37817 & 67513 & $18,1 \%$ & $37,7 \%$ & $25,5 \%$ \\
\hline $\begin{array}{l}\text { Oficiales, operarios y artesanos de artes } \\
\text { mecánicas y de otros oficios }\end{array}$ & 26698 & 3404 & 30102 & $16,2 \%$ & $3,4 \%$ & $11,4 \%$ \\
\hline Personal de apoyo administrativo & 10156 & 2289 & 12445 & $6,2 \%$ & $2,3 \%$ & $4,7 \%$ \\
\hline Profesionales, científicos e intelectuales & 3375 & 4813 & 8188 & $2,1 \%$ & $4,8 \%$ & $3,1 \%$ \\
\hline $\begin{array}{l}\text { Operadores de instalaciones y máquinas y } \\
\text { ensambladores }\end{array}$ & 7705 & 380 & 8085 & $4,7 \%$ & $0,4 \%$ & $3,1 \%$ \\
\hline Técnicos y profesionales de nivel medio & 7163 & 648 & 7811 & $4,4 \%$ & $0,6 \%$ & $2,9 \%$ \\
\hline $\begin{array}{l}\text { Agricultores y trabajadores calificados } \\
\text { agropecuarios, forestales y pesqueros }\end{array}$ & 3632 & 934 & 4566 & $2,2 \%$ & $0,9 \%$ & $1,7 \%$ \\
\hline Directores y gerentes & 98 & 1935 & 2033 & $0,1 \%$ & $1,9 \%$ & $0,8 \%$ \\
\hline Total & 164491 & 100358 & 264849 & $100,0 \%$ & $100,0 \%$ & $100,0 \%$ \\
\hline
\end{tabular}

Fuente: elaboración propia, con datos de la ECE del INEC.

\section{Ocupados inmigrantes por rama de actividad económica}

En la Tabla $\underline{7}$ se presentan 20 ramas de actividad económica ${ }^{7}$ y la correspondiente distribución de las personas ocupadas inmigrantes. De estas, en el nivel general, el $60 \%$ corresponde a cuatro actividades principales en las que se ubican estos trabajadores: a) "Comercio al por mayor y al por menor y reparación de vehículos de motores y de las motocicletas", b) "Actividades de los hogares como empleadores", c) “Agricultura, ganadería, silvicultura y pesca" y, d) "Construcción" (ver última columna de la Tabla $\underline{7}$ ).

La información desagregada por sexo también se presenta en la Tabla $\underline{7}$, donde se evidencia la división sexual del trabajo ${ }^{8}$, siendo que los hombres se dedican más a actividades agropecuarias,

\footnotetext{
7 Para clasificar la rama de actividad económica se toma como referencia la Clasificación Internacional Industrial Uniforme de todas las Actividades Económicas (CIIU revisión 4), (INEC, 2012).

8 "La división sexual del trabajo determina a las mujeres como responsables de la reproducción (trabajo doméstico, cuidado de niños, enfermos y adultos mayores), y a los hombres de la producción. En este sentido, a partir de esta asignación de tareas se constituyen relaciones de género en el ámbito económico y en la producción mercantil, lo cual limita el acceso igualitario de ellas a los recursos materiales y sociales: propiedad del capital productivo, de la tierra, trabajo remunerado, tecnología, educación y capacitación (Bravo, 2009). En otras palabras, la división sexual del trabajo en el ámbito doméstico se traslada a la división sexual del trabajo en el mercado laboral, donde se da una inserción laboral desventajosa y subordinada para las mujeres como consecuencia de que el mercado laboral excluye y segrega en función del sexo, a partir de diferencias reales o ficticias en la disponibilidad femenina y masculina que
}

64

Roxana Morales Ramos

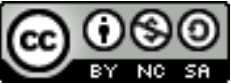

Revista Economía y Sociedad by Universidad Nacional is licensed under a CreativeCommons Reconocimiento-NoComercial- 
de construcción y comercio; y las mujeres, a labores como: trabajo doméstico, comercio y actividades de alojamiento y comida.

\section{Tabla 7}

Costa Rica: población ocupada nacida en otro país por rama de actividad del empleo principal según sexo. Il trimestre 2018

\begin{tabular}{|c|c|c|c|c|c|c|}
\hline Ocupado nacido en otro país & Hombre & Mujer & Total & Hombre & Mujer & Total \\
\hline $\begin{array}{l}\text { Comercio al por mayor y al por menor; } \\
\text { reparación de vehículos de motores y de } \\
\text { las motocicletas }\end{array}$ & 27991 & 15592 & 43583 & $17,0 \%$ & $15,5 \%$ & $16,5 \%$ \\
\hline $\begin{array}{l}\text { Actividades de los hogares como } \\
\text { empleadores }\end{array}$ & 6491 & 34241 & 40732 & $3,9 \%$ & $34,1 \%$ & $15,4 \%$ \\
\hline Agricultura, ganadería, silvicultura y pesca & 33615 & 4988 & 38603 & $20,4 \%$ & $5,0 \%$ & $14,6 \%$ \\
\hline Construcción & 34742 & 820 & 35562 & $21,1 \%$ & $0,8 \%$ & $13,4 \%$ \\
\hline $\begin{array}{l}\text { Actividades de alojamiento y servicios de } \\
\text { comida }\end{array}$ & 6760 & 18980 & 25740 & $4,1 \%$ & $18,9 \%$ & $9,7 \%$ \\
\hline $\begin{array}{l}\text { Actividades de servicios administrativos y } \\
\text { de apoyo }\end{array}$ & 12356 & 7853 & 20209 & $7,5 \%$ & $7,8 \%$ & $7,6 \%$ \\
\hline Industrias manufactureras & 16487 & 3251 & 19738 & $10,0 \%$ & $3,2 \%$ & $7,5 \%$ \\
\hline Otras actividades de servicios & 2813 & 5830 & 8643 & $1,7 \%$ & $5,8 \%$ & $3,3 \%$ \\
\hline Transporte y almacenamiento & 8220 & 140 & 8360 & $5,0 \%$ & $0,1 \%$ & $3,2 \%$ \\
\hline Enseñanza & 2990 & 3455 & 6445 & $1,8 \%$ & $3,4 \%$ & $2,4 \%$ \\
\hline Actividades inmobiliarias & 3190 & 715 & 3905 & $1,9 \%$ & $0,7 \%$ & $1,5 \%$ \\
\hline $\begin{array}{l}\text { Actividades profesionales, científicas y } \\
\text { técnicas }\end{array}$ & 1658 & 1105 & 2763 & $1,0 \%$ & $1,1 \%$ & $1,0 \%$ \\
\hline $\begin{array}{l}\text { Actividades de atención de la salud } \\
\text { humana y de asistencia social }\end{array}$ & 211 & 2190 & 2401 & $0,1 \%$ & $2,2 \%$ & $0,9 \%$ \\
\hline Información y comunicaciones & 2248 & 71 & 2319 & $1,4 \%$ & $0,1 \%$ & $0,9 \%$ \\
\hline $\begin{array}{l}\text { Administración pública y defensa; planes } \\
\text { de seguridad social de afiliación obligatoria }\end{array}$ & 1350 & 256 & 1606 & $0,8 \%$ & $0,3 \%$ & $0,6 \%$ \\
\hline $\begin{array}{l}\text { Actividades artísticas, de entretenimiento } \\
\text { y recreativas }\end{array}$ & 703 & 799 & 1502 & $0,4 \%$ & $0,8 \%$ & $0,6 \%$ \\
\hline Actividades financieras y de seguros & 895 & 72 & 967 & $0,5 \%$ & $0,1 \%$ & $0,4 \%$ \\
\hline $\begin{array}{l}\text { Actividades de organizaciones y órganos } \\
\text { extraterritoriales }\end{array}$ & 821 & - & 821 & $0,5 \%$ & $0,0 \%$ & $0,3 \%$ \\
\hline $\begin{array}{l}\text { Suministro de electricidad, gas, vapor y } \\
\text { aire acondicionado }\end{array}$ & 592 & - & 592 & $0,4 \%$ & $0,0 \%$ & $0,2 \%$ \\
\hline $\begin{array}{l}\text { Suministro de agua, evacuación de aguas } \\
\text { residuales y gestión de desechos y } \\
\text { contaminación }\end{array}$ & 358 & - & 358 & $0,2 \%$ & $0,0 \%$ & $0,1 \%$ \\
\hline Total & 164491 & 100358 & 264849 & $100,0 \%$ & $100,0 \%$ & $100,0 \%$ \\
\hline
\end{tabular}

Fuente: elaboración propia, con datos de la ECE del INEC.

tienen su origen en la distribución desigual de las cargas familiares entre mujeres y hombres". (Morales R., 2014, p. 36) 
A continuación, se presentan otros datos que se desprenden del análisis de las personas ocupadas inmigrantes en el segundo trimestre de 2018 (cálculos propios a partir de la ECE). Se presenta información para las siete ramas de actividad donde hay mayor participación de población migrante (se muestran de mayor a menor participación absoluta):

- Del total de personas ocupadas en el país en "Comercio al por mayor y al por menor; reparación de vehículos de motores y de las motocicletas" (374 536 personas), el 11,6 \% son inmigrantes (43 583 personas). De estos últimos, el 64,2\% son hombres (27 991) y $35,8 \%$ son mujeres (15 592).

- Del total de personas ocupadas en el país en "Actividades de los hogares como empleadores" (154 065 personas) el 26,4 \% son inmigrantes (40 732 personas). De estos últimos, el $84 \%$ son mujeres y el $16 \%$ hombres.

- Del total de personas ocupadas en el país en "Agricultura, ganadería, silvicultura y pesca" (254 220 personas), el 15,2 \% son inmigrantes (38 603 personas). De estos últimos, el 13 $\%$ son mujeres y el $87 \%$ hombres.

- Del total de personas ocupadas en el país en "Construcción" (173 613 personas), el 20,5\% son inmigrantes (35 562 personas). De estos últimos, el 97,7 \% son hombres (34 742) y $2,3 \%$ son mujeres ( 820$)$.

- Del total de personas ocupadas en el país en "Actividades de alojamiento y servicios de comida" (141 410 personas), el 18,2 \% son inmigrantes (25 740 personas). De estos últimos, el 73,7 \% son mujeres (18 980) y el $26,3 \%$ hombres (6 760$)$.

- Del total de personas ocupadas en el país en "Actividades de servicios administrativos y de apoyo" (113 808 personas), el 17,8 \% son inmigrantes (20 209 personas). De estos últimos, el $39 \%$ son mujeres (7 853) y el $61 \%$ hombres (12 356).

- Del total de personas ocupadas en el país en "Industria manufacturera" (233 998 personas), el 8,4 \% son inmigrantes (19 738 personas). De estos últimos, el 83,5 \% son hombres (16 487) y el $16,5 \%$ mujeres ( 3251 ).

De lo anterior se desprende que en el sector "Actividades de los hogares como empleadores" es en el que más participación relativa de inmigrantes hay $(26,4 \%)$, evidenciándose que en su mayoría son mujeres. Este es un sector históricamente feminizado y que, por tanto, es uno de los principales en que se incorporan las mujeres que cuentan con bajos niveles de educación y que requieren obtener ingresos propios. Además, es una actividad que les permite conciliar el trabajo remunerado con el no remunerado debido a la posibilidad de laborar en tiempo parcial. No obstante, es un sector de muy baja paga y donde existe mucha informalidad.

El segundo sector con mayor importancia relativa de la población inmigrante es "construcción" $(20,5 \%)$, del cual (97\% son hombres). A continuación, se mencionan cuatro hechos que podrían estar influyendo en estos resultados:

66

Roxana Morales Ramos

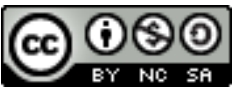

Revista Economía y Sociedad by Universidad Nacional is licensed under a CreativeCommons Reconocimiento-NoComercial- 
a) Es una actividad que, en mi opinión, no le gusta desarrollar a muchos costarricenses, tanto por el nivel de desgaste físico que implica como por los bajos salarios o remuneraciones que se obtienen.

b) Podría existir una segmentación del mercado laboral que ha "empujado" a las personas inmigrantes a realizar actividades que requieren bajo nivel de cualificación, que son mal remuneradas y de baja productividad.

c) La mayoría de la población inmigrante procede de Nicaragua y esta posee un bajo perfil educativo, lo que podría limitar su incorporación a otro tipo de actividades económicas.

d) Hay una gran cantidad de trabajadores en la informalidad $y$, posiblemente, las restricciones que los inmigrantes tienen para optar por permisos de trabajo (políticas de la Dirección de Migración y Extranjería y del Ministerio de Trabajo y Seguridad Social de Costa Rica, costos monetarios, entre otros), los obliga a laborar en actividades donde es más fácil desarrollarse informalmente (el sector construcción brinda puestos temporales y estacionales).

\section{Ocupados inmigrantes por posición en el empleo principal y seguro por trabajo}

En la Tabla $\underline{8}$ se presenta información sobre los ocupados inmigrantes según posición en el empleo. De la tabla resalta que alrededor del $81 \%$ de los ocupados nacidos en otro país laboran como asalariados, el $15 \%$ en cuenta propia y solo el 2,3 \% como empleadores. Estos datos reproducen la dinámica del empleo en el nivel nacional, es decir, la mayoría de la población ocupada labora como asalariada y muy poca como empleadora.

Tabla 8

Costa Rica: población ocupada nacida en otro país por posición en el empleo principal según sexo. II trimestre 2018

\begin{tabular}{lrrrrr} 
& Asalariado & Cuenta propia & Empleador & $\begin{array}{c}\text { Auxiliar } \\
\text { no remunerado }\end{array}$ & \multicolumn{1}{l}{ Total } \\
\hline Hombre & 134698 & 23595 & 5521 & 677 & 164491 \\
Mujer & 81932 & 16399 & 528 & 1499 & 100358 \\
\hline Total & $\mathbf{2 1 6} \mathbf{6 3 0}$ & $\mathbf{3 9 9 9 4}$ & $\mathbf{6 0 4 9}$ & $\mathbf{2 1 7 6}$ & $\mathbf{2 6 4 8 4 9}$ \\
\hline & & & & & \\
Hombre & $81,9 \%$ & $14,3 \%$ & $3,4 \%$ & $0,4 \%$ & $1000 \%$ \\
Mujer & $81,6 \%$ & $16,3 \%$ & $0,5 \%$ & $1,5 \%$ & $100,0 \%$ \\
\hline Total & $\mathbf{8 1 , 8 \%}$ & $\mathbf{1 5 , 1 \%}$ & $\mathbf{2 , 3 \%}$ & $\mathbf{0 , 8 \%}$ & $\mathbf{1 0 0 , 0 \%}$ \\
\hline
\end{tabular}

Fuente: elaboración propia, con datos de la ECE del INEC. 
Con respecto al seguro por trabajo, del total de inmigrantes ocupados, $72 \%{ }^{9}$ posee seguro por trabajo, el restante $28 \%$ no lo posee; es decir, no es cierto que la mayoría de las personas inmigrantes estén en la informalidad, como muchas personas piensan y, por tanto, la mayoría sí contribuye a la seguridad social de la cual hace uso (el asegurado directo y su familia).

\section{Otros indicadores de la población inmigrante ocupada}

- Subempleo visible ${ }^{10}$ : la tasa de subempleo por insuficiencia de horas, en el nivel nacional, ronda el $9 \%$ (entre los hombres el 6,9\% y entre las mujeres el 12,7\%), entre la población inmigrante es mayor, logra alcanzar el $11,2 \%$ (7,4 \% hombres y $17,4 \%$ mujeres). Este elevado subempleo podría estar explicado por el hecho de que muchas de las mujeres inmigrantes laboran en "Hogares como empleadores" siendo que estos comúnmente contratan servicios a tiempo parcial. Lo anterior pone de manifiesto nuevamente las brechas de género existentes en el mercado laboral, donde las mujeres son las que presentan las peores condiciones.

- Subempleo invisible ${ }^{11}$ : El 17,8 \% de las personas inmigrantes ocupadas en jornada de 40 horas o más, gana menos del salario mínimo en todos los empleos. En el caso de los hombres, el porcentaje es del $20 \%$ y en el de las mujeres el $14,1 \%$.

- Informalidad ${ }^{12}$ : El 51,9\% de los inmigrantes ocupados laboran en la informalidad. Entre las mujeres el porcentaje es del 60,7 \% y entre los hombres del 46,6\%. En el nivel país, la informalidad ronda el 44,7\% (mujeres: 48,7\%, hombres: 42,3\%). Estos datos denotan la elevada informalidad que sufren las mujeres y particularmente las inmigrantes.

\footnotetext{
${ }^{9}$ En el nivel nacional, solo el $68,6 \%$ de las personas ocupadas cuentan con seguro por trabajo, por tanto, se podría decir que el porcentaje de inmigrantes ocupados con seguro por trabajo es mayor que el promedio nacional (Mujeres: 61,6 \%; hombres: 72,7\%).

10 Porcentaje de la población ocupada que trabaja menos de cuarenta horas por semana (insuficiencia de horas), quiere trabajar más y está disponible para trabajar más horas de lo que su ocupación actual le permite (INEC, 2015).

11 Porcentaje de la población ocupada que trabaja más de 40 horas por semana y recibe menos del salario mínimo minimorum en todos sus empleos.

12 Características del empleo informal: personas asalariadas sin seguridad social financiada por su empleador, personas asalariadas que solo se le paga en especie o que el pago fue una única vez, personas ayudantes no remuneradas, personas trabajadoras por cuenta propia y empleadoras que tienen empresas no constituidas en sociedad, es decir, que no están inscritas en el Registro Nacional de la Propiedad y no llevan una contabilidad formal en forma periódica y, personas trabajadoras por cuenta propia con trabajos ocasionales (laboran menos de un mes) (INEC, 2015).
}

68

Roxana Morales Ramos

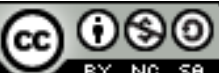

Revista Economía y Sociedad by Universidad Nacional is licensed under a CreativeCommons Reconocimiento-NoComercial- 
5. Perfil educativo de la población inmigrante en fuerza de trabajo (ocupada + desempleada)

De las 280752 personas inmigrantes en fuerza de trabajo

- El 5,8 \% no tienen ningún nivel educativo.

- El 17,8\% tiene primaria incompleta.

- El 21,1\% tiene primaria completa.

- El 26,3\% tiene secundaria incompleta (se podría decir que el $71 \%$ no ha terminado secundaria).

- El 16,3\% secundaria completa.

- El 2,8 \% son universitarios sin título.

— El 6,7\% son universitarios con título.

- El 0,1\% es no especificado.

Al desagregar la información anterior, por países de origen, se encuentran importantes diferencias en el perfil educativo de la población inmigrante, siendo los nicaragüenses, hondureños y panameños los de menor perfil; y los de otros países, estadounidenses, colombianos, venezolanos y mexicanos los de más alto perfil. Ver Tabla $\underline{9}$.

Tabla 9

Costa Rica: perfil educativo de la población inmigrante en la fuerza de trabajo por país de origen. II trimestre 2018

\begin{tabular}{|c|c|}
\hline Nicaragüenses (230 040 personas) & Otro país (13 683 personas) \\
\hline $\begin{array}{l}\text { - El } 7,1 \% \text { no tienen ningún nivel educativo. } \\
\text { - El } 21 \% \text { tiene primaria incompleta. } \\
\text { - El } 24,4 \% \text { tiene primaria completa. } \\
\text { - El } 29,2 \% \text { tiene secundaria incompleta. } \\
\text { - El } 13,9 \% \text { secundaria completa. } \\
\text { - El } 1,3 \% \text { son universitarios sin título } \\
\text { - El } 3 \% \text { son universitarios con título. }\end{array}$ & $\begin{array}{l}\text { - El 1,2\% tiene primaria incompleta. } \\
\text { - El 3,4\% tiene primaria completa. } \\
\text { - El 14,7\% tiene secundaria incompleta. } \\
\text { - El } 6 \% \text { secundaria completa. } \\
\text { - El } 2,1 \% \text { son universitarios sin título } \\
\text { - El } 72,6 \% \text { son universitarios con título. }\end{array}$ \\
\hline Colombianos (11 560 personas) & Hondureños (6 643 personas) \\
\hline $\begin{array}{l}\text { - El } 10,1 \% \text { tiene secundaria incompleta. } \\
\text { - El } 40,2 \% \text { secundaria completa. } \\
\text { - El } 17,8 \% \text { son universitarios sin título } \\
\text { - El } 32 \% \text { son universitarios con título. }\end{array}$ & $\begin{array}{l}\text { - El } 1,2 \% \text { tiene primaria incompleta. } \\
\text { - El } 21,6 \% \text { tiene primaria completa. } \\
\text { - El } 20,7 \% \text { tiene secundaria incompleta. } \\
\text { - El } 35,2 \% \text { secundaria completa. } \\
\text { - El } 21,3 \% \text { son universitarios con título. }\end{array}$ \\
\hline
\end{tabular}




\begin{tabular}{|c|c|}
\hline Panameños (5 502 personas) & Estadounidenses (4 878 personas) \\
\hline $\begin{array}{l}\text { - El } 1,6 \% \text { no tienen ningún nivel educativo. } \\
\text { - El } 25,6 \% \text { tiene primaria incompleta. } \\
\text { - El } 17,3 \% \text { tiene primaria completa. } \\
\text { - El } 5,5 \% \text { tiene secundaria incompleta. } \\
\text { - El } 45,8 \% \text { secundaria completa. } \\
\text { - El } 4,3 \% \text { son universitarios con título. }\end{array}$ & $\begin{array}{l}\text { - El } 5,3 \% \text { tiene secundaria incompleta. } \\
\text { - El } 38,7 \% \text { secundaria completa. } \\
\text { - El } 20,4 \% \text { son universitarios sin título } \\
\text { - El } 35,6 \% \text { son universitarios con título. }\end{array}$ \\
\hline Venezolanos (4 280 personas) & Mexicanos (2 688 personas) \\
\hline $\begin{array}{l}\text { - El } 26,5 \% \text { tiene secundaria } \\
\text { - completa. } \\
\text { - El } 15,5 \% \text { son universitarios sin título } \\
\text { - El } 58 \% \text { son universitarios con título. }\end{array}$ & $\begin{array}{l}\text { - El } 33,1 \% \text { tiene secundaria incompleta. } \\
\text { - El } 36,1 \% \text { son universitarios sin título } \\
\text { - El } 30,8 \% \text { son universitarios con título. }\end{array}$ \\
\hline \multicolumn{2}{|l|}{ Salvadoreños (1 371 personas) } \\
\hline $\begin{array}{l}\text { - El 4,4\% tiene primaria incompleta. } \\
\text { - El } 9 \% \text { tiene primaria completa. } \\
\text { - El } 44 \% \text { tiene secundaria incompleta. } \\
\text { - El } 30 \% \text { secundaria completa. } \\
\text { - El } 11,7 \% \text { son universitarios con título. }\end{array}$ & \\
\hline
\end{tabular}

Fuente: elaboración propia, con datos de la ECE del INEC.

\section{Conclusiones}

- Costa Rica es un país receptor de personas migrantes, principalmente de personas nicaragüenses; no obstante, también recibe población de diversas partes del mundo. Dentro de los resultados es importante mencionar que a pesar de que, como promedio nacional, la población inmigrante a) presenta un perfil educativo bajo, b) es relativamente joven y, c) hay más mujeres que hombres; al desagregar la información por regiones, por país de origen, o por sexo, los resultados varían considerablemente, es decir, existen muchas diferencias según el grupo de población inmigrante que se analice. Por ejemplo, a) el perfil de los inmigrantes que provienen de Nicaragua difiere del perfil de los que provienen de Panamá, El Salvador o cualquier otro país; b) el perfil de las mujeres inmigrantes es diferente al de los hombres inmigrantes, y varía también según el país de procedencia. En síntesis, existen particularidades en cada grupo de población inmigrante analizado, por lo que resulta necesario considerar estas diferencias a la hora de plantear políticas públicas en materia migratoria.

- El análisis realizado también permitió constatar que dentro de la población inmigrante se reproduce, del mismo modo, la llamada división sexual del trabajo, de forma tal que las mujeres se dedican más a labores domésticas y en actividades de alojamiento y servicios,

70

Roxana Morales Ramos

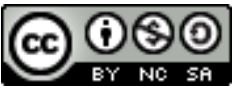

Revista Economía y Sociedad by Universidad Nacional is licensed under a CreativeCommons Reconocimiento-NoComercial- 
mientras que los hombres se dedican más a labores agrícolas y de construcción. Lo que sí tienen en común los hombres y mujeres inmigrantes, es que en su mayoría se dedican a actividades que requieren bajo nivel de cualificación y con bajas remuneraciones.

- En el caso de las mujeres, se reproduce en la población inmigrante, las mismas brechas de género que se presentan en el nivel nacional, es decir, enfrentan mayores tasas de desempleo, de subempleo, de informalidad, menor participación en la fuerza de trabajo, las que laboran lo hacen mayoritariamente en aquellas actividades típicamente feminizadas y con bajos niveles de remuneración, entre otros. Este es un reto país que debería ser prioridad en las políticas públicas: la igualdad y equidad de género.

- La población inmigrante realiza un importante aporte a la economía nacional. En una reciente investigación realizada por la Organización de Cooperación y Desarrollo Económicos (OCDE) y la Organización Mundial del Trabajo (OIT), se determinó que el aporte de los inmigrantes a Costa Rica ronda el $12 \%$ del PIB, (OCDE y OIT, 2018), un porcentaje para nada despreciable. Asimismo, una investigación realizada por Gustavo Gatica (2018), titulada "Aportes de las personas migrantes y refugiadas a la creación de riqueza en Costa Rica" demostró que el aporte de esta población al PIB nacional es de aproximadamente $11,32 \%$.

- Finalmente, vale la pena señalar que el incremento en la inmigración, producto de la crisis que se vive en Nicaragua, e incluso en Venezuela (que también provoca un aumento en el ingreso de venezolanos a Costa Rica), podría tener impactos, tanto en materia económica como social, ya que se generan más presiones sobre el mercado laboral, en un contexto nacional donde existe un alto nivel de desempleo, producto del desenganche entre el crecimiento económico y el crecimiento del empleo ${ }^{13}$, así como por problemas estructurales que limitan el crecimiento de la economía, entre ellos el elevado y creciente déficit fiscal. Por su parte, en materia social, el principal reto está en no permitir que la xenofobia se apodere de la población, y más bien el país logre dar apoyo a muchos inmigrantes que buscan refugio, claro está, con ciertos límites y con apoyo de la comunidad internacional.

${ }^{13}$ Ver: Desempleo: un problema estructural en Costa Rica (Morales R., 2017). 
Referencias

Banco Central de Costa Rica (2018). Aspectos socioeconómicos de las remesas familiares en Costa Rica, $2016 . \quad$ Recuperado de https://activos.bccr.fi.cr/sitios/bccr/publicaciones/DocPoliticaCambiariaSectorExter no/ASRFCR 2016.pdf

Chinchilla, S. (2018, 16 de julio). Aumentan solicitudes de visas a Costa Rica en Nicaragua. Periódico La Nación. Recuperado de https://www.nacion.com/elpais/politica/aumentan-solicitudes-de-visas-a-costa-ricaen/YESS3GDU4VGD3PN3FRPCNZEBDQ/story/

Gamboa, S. (2008). ¿Qué es la perspectiva de género y los estudios de género? En Mujeres en Red. El periódico feminista. Recuperado de http://www.mujeresenred.net/spip.php?article1395

Gatica, G. (2018). Aportes de las personas migrantes y refugiadas a la creación de riqueza en Costa Rica. Revista Rupturas, 1(8), 71-100. Recuperado de http://investiga.uned.ac.cr/revistas/index.php/rupturas/article/view/1974/2248

Instituto Nacional de Estadística y Censos (INEC). (2012). Métodos y procedimientos: Encuesta Continua de Empleo. Recuperado de http://www.inec.go.cr/sites/default/files/documetos-bibliotecavirtual/meecemetodos 01.pdf

Instituto Nacional de Estadística y Censos (INEC). (2015). Encuesta Continua de Empleo: Empleo informal, fecha metodológica. Recuperado de http://www.inec.go.cr/sites/default/files/documetos-bibliotecavirtual/meeceempleo informal06.pdf

Instituto Nacional de Estadística y Censos (INEC). (2016). Manual de Clasificación Geográfica con Fines Estadísticos de Costa Rica. Recuperado de http://www.inec.go.cr/sites/default/files/documetos-bibliotecavirtual/meinstitucionalmcgfecr.pdf

Jiménez, B. y Recio, P. (2018, 25 de junio). Nicaragüenses que buscan refugio en Costa Rica saturan sede central de Migración y Extranjería. Periódico La Nación. Recuperado de https://www.nacion.com/sucesos/seguridad/nicaraguenses-que-buscan-refugio-encosta-rica/RWOYMPIAKFBKVJVW5VXTQ30V5A/story/

72 
Morales, A. (2008). Serie Población y Desarrollo N85: Inmigración en Costa Rica: características sociales y laborales, integración y políticas públicas. Santiago de Chile: Centro Latinoamericano y Caribeño de Demografía (CELADE) - División de Población de la CEPAL. Recuperado de https://repositorio.cepal.org/bitstream/handle/11362/7225/S0800525 es.pdf?sequ ence $=1 \&$ isAllowed $=y$

Morales, R. (2014). Inequidades socioeconómicas y laborales de género en Costa Rica en el periodo 2000-2013: diagnóstico y propuestas. (Trabajo final de graduación para optar por el grado de Licenciatura en Economía, Universidad Nacional, Costa Rica). Recuperado de https://goo.gl/ZECEGt

Morales, R. (2017). Desempleo: un problema estructural en Costa Rica. En Campus Digital UNA: Pinceladas de la realidad nacional. Recuperado de http://www.campus.una.ac.cr/ediciones/2017/noviembre/2017noviembre_pag23a. $\underline{\text { html }}$

Organización de Cooperación y Desarrollo Económicos (OCDE) \& Organización Mundial del Trabajo (OIT). (2018). Cómo los inmigrantes contribuyen a la economía de Costa Rica. París: Organización de Cooperación y Desarrollo Económicos. DOI: https://doi.org/10.1787/9789264303867-es 